AC 2009-1802: ATYPICAL SENIOR CAPSTONE PROJECTS: THE PROCESS IS THE PRODUCT

\author{
C. Richard Helps, Brigham Young University \\ Bret Swan, Brigham Young University
}




\title{
Atypical Senior Capstone Projects: The Process is the Product
}

\begin{abstract}
Senior capstone projects in Engineering and Technology disciplines teach students valuable skills in design, teamwork, project management and related skills. Almost always these learning objectives are achieved through student teams building a working prototype or simulation of a product or system. However there are other ways that students can exercise their technical design skills and participate in capstone projects to achieve substantive deliverables that do not result in a working product or system.

Students building a working prototype product or system are operating in primarily in the product-oriented, phase of the complete system development life cycle. There are hidden assumptions in the design of capstone courses that encourage students to work in that phase.

A student team can accomplish the learning objectives of a technical capstone project by following a clearly defined design and development process resulting in project deliverables that are not a working prototype.

Recently, an Information Technology (IT) capstone student team at Brigham Young University selected a project that requires them to follow a systems analysis and design methodology to design and user-test information technologies that facilitate strong family relationships Ensuring that the team is developing the right solution becomes a significant project in itself, requiring a system development process as well as technical skills.

The challenge of this capstone experience is framing the project in terms of the systems analysis and design process, rather than a product, as the deliverable of the class, while ensuring that the learning experience meets the course objectives. We report on challenges and successes of this direction, with suggestions of how this could lead to better capstone education.
\end{abstract}

\section{Introduction}

A complete product or system development lifecycle covers far more than is covered in a typical capstone design course experience. Complete lifecycles include planning and analysis phases, build and test phases, implementation and maintenance phases among others. Some disciplines, such as industrial Design, focus on earlier stages of the design lifecycle, producing final "designs" which are often a set of drawings for a conceptual future product. Information Systems students with their strong business influence often complete projects that focus on analysis of user needs rather than production of a working system. Engineering and technology disciplines, including Information Technology, often have a more technical orientation. Very frequently capstone engineering and technology projects from engineering and technology disciplines are product-oriented, focusing on the build and test phases of development. This emphasis is reflected in several publications on engineering and technology capstone courses. Todd et al. indicate this in their comprehensive 1995 survey results ${ }^{1}$ by stating that "Projects ... generally require the team to design and manufacture a system" and further state that different engineering departments have different expectations for their students, but that in general students are designing a product or system of simulation of one. 
"There are numerous articles about individual Capstone courses in the literature. A few are referenced as examples. Capstone courses in mechanical engineering have included projects that require either the design or the design and manufacture of a project's solution. Courses in civil engineering generally emphasize only the design. Many capstone courses in electrical and computer engineering include design, fabrication, and testing of a product. Chemical engineering capstone courses focus mainly on experimental research." (Citations from original article omitted)

In 2005 Howe and Wilbarger followed up the 1995 study with a second comprehensive national study ${ }^{2}$ where they list the primary concerns or topics of programs in engineering and technology offering capstone experiences. Table 1 shows these topics ranked by frequency of programs offering them

\begin{tabular}{|l|l|}
\hline Topic & $\%$ \\
\hline Written Communication & 87 \\
\hline Oral communication & 83 \\
\hline Engineering Ethics & 76 \\
\hline Project Planning and Scheduling & 72 \\
\hline Decision making & 68 \\
\hline Teambuilding & 66 \\
\hline Team Dynamics & 63 \\
\hline Engineering Economics & 61 \\
\hline Developing/Writing Functional Specifications & 56 \\
\hline Safety in Product design & 52 \\
\hline Leadership & 50 \\
\hline Drawing/Creativity/Concept Generation & 48 \\
\hline Analysis Tools & 46 \\
\hline Intellectual Property/Patents & 45 \\
\hline Prototyping and Testing & 37 \\
\hline Optimization & 34 \\
\hline Sustainability & 29 \\
\hline Manufacturing Processes & 29 \\
\hline Risk Assessment & 29 \\
\hline CAD Design and Layout & 29 \\
\hline Product Liability & 24 \\
\hline Quality Function Deployment & 17 \\
\hline Other & 13 \\
\hline
\end{tabular}

Table 1 from (Table 1, Howe and Wilbarger, 2005)

What is noticeable from this study is what is missing. There little or no emphasis on user needs or user testing. The closest topics are "Drawing/Creativity/Concept Generation", taught as a topic in $48 \%$ of the programs, or possibly "developing/Writing functional specifications". However it is unlikely that either of these have a strong emphasis on user needs. This observation agrees with our own twenty-plus years of experience of capstone courses in Engineering and Technology.

As a result of this emphasis in goals on the product end of the system development life cycle these projects often neglect the important user-centered analysis, design, test, and 
implementation phases of the development lifecycle. Consequently, user-oriented projects can be ignored when choosing technical capstone projects.

The necessity of considering user needs is well recognized as important in the complete cycle. Determining needs requires input from both users and from system analysts (designers) ${ }^{3}$. In considering this need it is important to distinguish between "sponsors", who often propose and pay for capstone projects, and "users" who buy and use the products that are ultimately manufactured and sold. Sponsors have considerable input into the process and their expressed needs are considered but there can be a disconnect between sponsors' stated needs and what users actually want, need and will pay for.

The purpose of this paper is to illustrate how user-oriented projects, that require emphasis on phases of the product or system development lifecycle other than the product-centered build and test phase should still be considered appropriate "Capstone" projects in engineering and technology disciplines. Such projects do not produce a working prototype product or system but do follow a well-defined design process with assessable deliverables.

This paper accomplishes this goal by comparing capstone project criteria from previous studies. Typical learning outcomes for capstone courses are identified. Unstated or hidden assumptions are identified in capstone projects taught across engineering and technical disciplines relative to the complete product and system development lifecycle. We then illustrate that a capstone can focus on a user-oriented development process, rather than a product oriented design of a product or system. We use a case study of a current project that requires a focus on user-centered humancomputer interaction (HCI) design in the development of Information Technology (IT) to support strong families. We show that all the important learning outcomes can be accomplished with a capstone project of this type, while yielding valuable deliverables for the customer.

\section{The goals of capstone courses}

Capstone courses have been popular in engineering and technology curricula over the last few decades. They provide a number of benefits for integrative and experiential learning and for meeting program outcomes for students that are not easily satisfied in typical technical classes.

Many papers have been written on the expected and actual outcomes of capstone courses. The 1995 survey by Todd et al. ${ }^{1}$ listed common expectations of many engineering programs. These include team issues, creativity issues, and technical issues. The 2005 Howe and Wilbarger study ${ }^{2}$ survey included the following list for subjects most frequently taught. (extract from Table 1). This section of the list shows topics taught by more than $50 \%$ of the respondents.

- Topic

- Written Communication

- Oral communication

- Engineering Ethics

- Project Planning and Scheduling

- Decision making 
- Teambuilding

- Team Dynamics

- Engineering Economics

- Developing/Writing Functional Specifications

- Safety in Product design

Another study examined the standardization of capstone course outcomes. In, "How Universal are Capstone Design Course Outcomes," Davis, Beyerlein et al. ${ }^{4}$ developed a list of attributes for the best outcomes:

"The attributes of top quality engineers include: (1) motivation, (2) technical competence, (3) judgment and decision making, (4) innovation, (5) client/quality focus, (6) business orientation, (7) product development, (8) professional/ethical, (9) teamwork, (10) change management, and (11) communication"

Other studies are also available. Many of them refer back to the 1995 study of Todd, Magleby et al. There is a high degree of congruency among the course outcomes of these different course designs. Most of the studies have focused on engineering courses rather than the slightly broader goal of engineering and technology, however most technology programs would be comfortable with the list of expected outcomes. Our own departmental experience with teaching capstone courses in Engineering Technology and Information Technology programs in general agrees with these results, in that these, or similar outcomes, are considered important in our own capstone project course.

The general attributes shown above will therefore be considered as a reasonable representation of the primary outcomes expected in a technical capstone course. Some adaptation can be expected in using this list in technology courses rather than engineering courses. For example 'Engineering Ethics' and 'Engineering Economics' are simplified to 'Ethics' and 'Economics'. In general a capstone course should substantively cover the listed topics.

In addition to the listed topics all, or nearly all, technical capstone courses include a number of other inherent or assumed attributes or assumptions. Some important assumptions will be made explicit.

\subsection{Hidden assumptions}

\subsection{Where in the design cycle does the experience take place?}

Development methodologies vary in terminology and specifics depending on the discipline. However, the primary development phases include a Planning Phase, an Analysis Phase, a Design Phase, a Build \& Test Phase, an Implementation Phase, and a Maintenance Phase. In the planning phase, the project is scoped, documented, planned, and approved. In the analysis phase, requirements are generated for the system or product using different analysis, modeling, and documentation methods. The design phase takes the requirements and converts them into a final set of system or product specifications using different design, prototyping, and evaluation methods. The build \& test phase builds the complete product or system and then follows testing 
procedures to make sure it confirms to the requirements and specifications. The implementation phase includes change management, training, and other methods designed to successfully transfer the product or system into production or everyday use. Lastly, the maintenance phase includes plans for ongoing maintenance, repairs, training, and ultimately the replacement and salvage of the system or product. ${ }^{5-9}$

As we have discussed above most projects in engineering and technology fall largely within the build \& test phase of the complete development life-cycle. Many capstone projects have the students build a product or simulation, a tangible artifact that performs according to the specifications that they are given or that they develop themselves. Sometimes the outcome is a system, where the students will integrate and combine several existing products to create a new solution for an identified problem. Although this building of a product, simulation or system is a common factor in capstone projects it is not stated explicitly as a learning goal. It is rather considered to be a vehicle through which the learning can take place. Build and test projects provide an excellent platform for students to develop the desired skills and attributes. They follow a process of design and development, which requires them to deal with customer communications, teamwork, project scheduling, design prototyping, exercise technical understanding, technical writing and formal presentations. As they follow this process they achieve the desired learning outcomes, but they are not the only way to meet these learning goals in technical disciplines.

This hidden assumption of product orientation in engineering and technology capstone courses is a significant issue because building a product or system for a customer provides an authentic learning experience for the students. ("Authentic" here is used in the instructional design sense, IE a learning experience that closely reflects the professional practice the students will enter into upon graduation.) Students pursuing authentic experiences in this manner show great enthusiasm for learning both because the degree of control they perceive that they have over the process and because they sense that they are engaged in projects that are important to a real customer, IE they are aware of and motivated by the authenticity of the project.

Product development is not the only way for students to enjoy the benefits of authentic capstone experiences. Most engineering and technology students will not spend their technical careers in this phase of the system development lifecycle. They will spend much of their times moving up and down the development lifecycle as necessary. Therefore authentic, interesting and challenging technical capstone experiences can be designed around different sections of the system development lifecycle.

\subsection{Capstone or just design?}

Another hidden assumption is that the course is a 'capstone'. IE the experience builds on a foundation of core courses in the major discipline. It is perfectly feasible for, say, a computer science major, to participate in a mechanical engineering design project which includes no computing aspects. Such a student may well learn teamwork, project management, customer liaison, and communication skills among others. They could have participated in a very rewarding design course but it is not a capstone course for them if it is not calling on the professional skills of their discipline.

For a course to be a valid capstone course it needs to draw on the core disciplines of the students' 
major field of study, as well as explore necessary topics such as teamwork, scheduling and so forth.

\subsection{The question for this experiment}

The question we asked is whether it is possible for a team of students to follow a valid technical design process addressing a different part of the development life cycle IE to follow the design process but not pursue product-oriented design. For this to be a successful capstone experience students should still experience the excitement of pursuing goal they are committed to, achieve project success and learn the desired attributes and skills. At the end of the capstone course they will not have developed a working prototype product but they will have demonstrated completion of a challenging technical process that accomplishes all the necessary learning goals as well as achieving measurable deliverables.

While the preceding statement sounds paradoxical it can be achieved. We report on an experiment conducted with a senior project team. In setting up senior projects for the previous academic year we had a team with a strong interest in applying techniques for Human-Computer Interaction (HCI). HCI is identified as a core technical skill for Information Technology programs $^{10}$ (See Appendix A - The Body of Knowledge). Core technical skills can be the center of a HCI-oriented capstone design project just as networking, programming or database design are at the core of other IT projects. The significant difference with HCI design is that it does not inherently produce a new product; rather it is the process of integrating human considerations into the design of other products. In the early stages of HCI design user considerations and the goals of the development team are intensely considered but the design of specific product solutions is avoided initially to ensure that the correct problem is solved rather than producing a product then looking to see what user needs it may satisfy. This early stage of problem solving requires a set of skills including design thinking, concept prototyping, persona development and in-depth empathetic understanding of user needs and desires. Properly pursued this form of design requires HCI skills combined with technical skills to generate new designs, which will later be developed into products that solve well-substantiated problems and improve the life of users and therefore benefit the organizations that supply them. The outcome of an HCI design process of this type is not a working prototype product but a package of deliverables including concepts, descriptions of user needs, and specifications for products or systems, with thoughtful design of the interface and the basic structure of the product(s) or system to be built. Coming from a technology background the design team should show a depth of understanding of the technical issues facing the product design.

In order to achieve high quality results, such as those described above the designers (students) need to follow a reliable design and development process that requires discipline, technical skill, and creative design work. All the attributes for successful capstone courses will be required by the students, some to an enhanced degree.

\section{The case study senior capstone design project}

The capstone project that was selected was the result of several previous years of research into the area of family technology. An on-going research project within the department, called "YHome", was investigating "family-friendly" technologies (i.e., technology products and systems intended to enhance family interactions rather than to denigrate them). Much has been written on 
the negative effects of some technologies in the home, which will not be re-iterated here. A study by the Princeton PEW Internet and Family Life Project identified technology influences in family life. The Pew study ${ }^{11}$ provided a much more nuanced picture of the role of technology in family interactions showing positive and negative influences. It provided statistics of how some technologies are being used and how they are influencing family communications.

It is the hope of the research group to develop and promote technologies designed not to intrude and interfere with family life but rather to enhance it. Previous work by this group has resulted in a few products, which, while technically feasible, aroused little interest in the target audience. They were designed by product-oriented researchers or teams who developed a solution in the hope that users would want it. From this experience the Y-Home group sponsored a project to ensure that the correct questions were being addressed and that products likely to be of significant benefit were being developed. This is the goal of the capstone project.

To comply with the expectations of a capstone project the team followed established best practices for design and development of user-oriented systems in this phase of the complete development life-cycle. They drew upon core disciplines required for students in the major; in this case the primary subject area was Human-Computer Interaction (HCI). In addition to HCI skills the students used their technical knowledge of networking, databases, programming, web systems and other technical skills in creating potential solutions and assessing them for feasibility. They are also required to develop teamwork, customer liaison skills, and employ creativity in proposing new solutions.

Their capstone process included an analysis phase, a design phase, a validation phase and a production phase.

The analysis phase includes:

A. Review of family science research to identify common traits or factors that build strong families.

a. A number of references were found which discuss the relationship between technology and families and also define characteristics of strong families. ${ }^{11-15}$

B. Review of IT-related literature to identify what effects different information technologies have had on families.

C. Defining target users demographic

a. The selected user characteristics were: Caucasian families with 1 or more children old enough to use computers and cell phones located in proximity to the university. This provides a baseline for future research and comparison across cultural and socio-economic demographics.

D. Creation of semi-structured interview and observational data gathering procedures.

E. Interview and analyze data from $20+$ families to identify common trends, priorities, and preferences that IT can be designed to support.

F. Document these results as a list of requirements to guide the design of family-supporting 
IT solutions.

The design phase includes:

G. Iterative design and prototyping of the user interfaces and IT functions to meet user requirements.

a. It should be noted that these prototypes are not fully functioning products or systems; they are a mixture of low and medium fidelity prototypes, such as wireframes, façades, models etc., which are standard design tools in the HCI discipline.

The validation Phase includes:

H. Review the designed prototypes for technical feasibility and modify or extend designs as necessary to allow for current IT technology capabilities. This is, perhaps, where the students' other core IT technical skills will be most evident.

The production phase includes:

I. The integration of designs for the user interfaces and IT functions into reports, specifications, presentations, prototype models, and any other means for effectively conveying the user needs, design ideas and technical constraints and proposals for the building and testing of a complete IT system.

\subsection{Deliverables}

An important aspect of this project is the deliverables. They need to be concrete deliverables and still be a normal part of the process, rather than a single product at the end. The deliverables evolved somewhat as the project progressed but the final list consists of the following.

1. Documentation of the process: this is important so that future designers can follow the development of the needs and specifications and see the reasoning behind them as they develop products.

2. Documentation of family characteristics, interactions with existing technology and identified needs.

3. Design Proposals: here is where the team exercised their creativity and combined their own ideas with input from users to develop new solutions. Solutions have varying granularity IE small items to major systems, but each is described in terms of meeting the identified user needs. Each of these proposals is a potential future product with justification of how it can tie into family needs.

4. Detailed prototype development: The most promising proposal was selected further design, prototyping and development and for user testing. The final deliverable is a technical specification of the future product with both technical considerations and user considerations taken into account. 
In the coming year, other capstone or graduate teams will advance to the further stages of the complete development life cycle and design and build working prototype devices and systems. Because of the results of this capstone team it is expected that these future products and systems will meet real needs of the intended user group and be easier to design and complete.

\section{Challenges and misperceptions to overcome}

\subsection{Expectation of product-oriented design}

The single largest challenge that the team faced in pursuing this project was the hidden assumption that unless they developed a working prototype of a device then it wasn't a 'real' project. The process of determining user needs and HCI design is perceived as merely preliminary to the 'real' work of developing a working prototype artifact.

This challenge was identified before the project was started but it was not realized how pervasive this thinking is. This hidden assumption is so prevalent that the authors, who are the faculty responsible for this project, found themselves slipping into the product-development mindset from time to time and advising students in that direction, and the students in the capstone team report that they have to consciously restrain themselves from leaping to product solutions before assessing the needs.

The extent this is a problem was illustrated by the responses to the students' mid-year presentations of their projects. Each of the capstone teams presented their work to an audience of faculty and IAB members. All the projects except this experimental one were typical productoriented designs. The students of this design team stated in their presentation that it was not their goal to complete a working prototype but to follow a design process, resulting in outcomes which would lead to future designs. The comments of the faculty and IAB members are summarized in Table 2 below.

\begin{tabular}{|c|c|}
\hline R01 & $\begin{array}{l}\text { I like the project but it will be a challenge to be successful because your } \\
\text { result/product may be difficult to quantify-make sure to stay focused on producing } \\
\text { something. }\end{array}$ \\
\hline R02 & $\begin{array}{l}\text { I wasn't sure what would be built for the project. I think it would have been useful } \\
\text { to describe what the first prototype would be. Is this just a research project? }\end{array}$ \\
\hline R03 & $\begin{array}{l}\text { I can see how they can develop a specification for new technology. However, I don't } \\
\text { see that they will have the time to create the technology. }\end{array}$ \\
\hline R04 & $\begin{array}{l}\text { My take-away was that this is a project that will spawn other projects in the future. } \\
\text { That should have been stated up-front. Half-way through the semester they aren't } \\
\text { sure what they are going to build. Are you really going to have working prototypes } \\
\text { by April? }\end{array}$ \\
\hline R05 & Excellent Project! Crucial research-an invaluable exercise. \\
\hline R06 & $\begin{array}{l}\text { How were the categories determined? Was there no concern regarding economics? } \\
\text { How about tools to enhance homework and study? }\end{array}$ \\
\hline
\end{tabular}




\begin{tabular}{|l|l|}
\hline R07 & $\begin{array}{l}\text { It must have been hard not to jump in and propose technologies and gadgets. They } \\
\text { are keeping to their plan. }\end{array}$ \\
\hline R10 & How do you collect prototype user data? Auto? Track clicks? \\
\hline R11 & Preliminary research is tough to call a "project." \\
\hline R12 & $\begin{array}{l}\text { I would have expected a little more concrete of a direction by this point in the year. } \\
\text { To get from here to a finished product looks like a lot. }\end{array}$ \\
\hline
\end{tabular}

Table 2. Comments from IAB members and faculty at the mid-year evaluation

Clearly, despite the team's statements, several of the evaluators were expecting a productoriented design approach and the team scored poorly because they did not have one. The comments from respondents R02, R03, R04 and R12 and in a sense, R01 indicate that unless the team knew what they were going to build then the project could not fully succeed. Respondent R11 apparently did not perceive what the team is doing as design or as part of the complete design cycle. Comments R05 and R07 indicate an understanding of the team's scope of work. The contrast between comments R07 and R02 is illuminating. The team stated that they were not committing to a product solution until they had fully understood the needs. R07 accepted this as a strength this whereas R02 felt this was a weakness. Apparently the team needs to better present their case in terms of the complete development life-cycle and the design phase they are in. These mid-year assessments are valuable feedback for the team. Addressing these perception issues for the year-end presentations will be discussed later in this report.

\subsection{Contribution of core technical skills}

For this project to be both appropriate for technology majors and a valid capstone experience building on students' technical skills there needs to be a clear contribution from core disciplinary skills to the project relating to those skills. Psychology, Marketing and Industrial Design students also work in these earlier sections of the complete design life cycle to develop product proposals. To be demonstrably an IT capstone project the students need to bring to the process an understanding of the technical designer as well as those of the non-technical user. Their design process must use their technical background to seek problems and solutions that reflect this technical depth. $\mathrm{HCI}$ is a core discipline in IT but more than one core discipline should be addressed. In this specific project some evidences that the students are meeting this criterion occur both in the design and validation phases of the process described above. In the design phase proposed solutions must be influenced by the student' understanding of the underlying technologies and in the validation phase the solutions must be specifically analyzed and feasible IT technical solutions must be specified.

\subsection{Addressing these challenges and misperceptions}

There is a common solution for all these challenges. The solution is for the team and faculty to address the challenges with an understanding of the hidden assumptions identified earlier. The solution then requires the following:

1. Use a best-practices process that reflects the professional practice of the relevant technical discipline. 
2. Ensure that the capstone project addresses the both explicit and hidden expectations. Reveal hidden expectations and make them explicit.

3. Clearly establish project deliverables that can be assessed.

4. Gain approval from stakeholders for the process and for the deliverables. The stakeholders include the customer, the faculty supervising the project and those who will evaluate the final project. In our case this includes the IAB.

\section{How this project meets capstone project criteria}

For our case study project we took care to ensure learning goals and expectations for the team were met. The capstone course teaches and requires the following for all capstone teams including the team in this case study.

1. Training and expectations in teamwork

2. Leadership

3. Project scheduling and management

4. Change management,

5. Customer communications,

6. Technical communication (oral and written)

7. Ethics

8. Innovation and creativity

9. Authenticity

Since all teams meet these requirements and these requirements match most of the goals of capstone courses then these capstone goals will be met.

The items that do not appear in the list primarily come from the hidden assumptions. Extra care was taken with this project to ensure that the team was using technical skills relating to core competencies in the major. In addition extra time was taken to discuss and clarify deliverables for this team. Care was also taken to ensure that the design and development process reflected best practices. Therefore all the learning objectives addressed earlier for technology capstone projects, with due consideration for hidden assumptions and authenticity, are effectively met.

\section{Conclusion}

Engineering and technology students can have valid exciting and capstone experiences by participating in different parts of the complete system design lifecycle. It is not necessary for them to pursue a product-oriented project, other projects, such as user-oriented projects, can provide rewarding and valid experiences but they must follow a well-defined process. 
The criteria necessary for such process-oriented capstone projects are

- To be a capstone experience it needs to draw on core topics in the discipline

- As for product-oriented projects, the project must be defined in terms of best practices for the professional discipline.

- The project must have clearly defined and measurable deliverables that draw on the core disciplinary skills of the students.

- The project must meet all the requirements of the capstone course such as teamwork, project management and other learning goals.

Since the deliverables for such projects are not a working prototype product or system a valid process must be followed to ensure that learning goals are met.

Considering projects in other parts of the development life cycle opens up many more possibilities for exciting and productive learning experiences for students in capstone classes. Our experience in this area has encouraged us to plan future projects following the guidelines we have developed. We recommend that all those designing capstone courses consider these broader horizons in setting projects.

\section{Bibliography}

1. R. H. Todd, S. P. Magleby, C. D. Sorenson, B. R. Swan, and D. K. Anthony, "A Survey of Capstone Engineering Courses in North America," Journal of Engineering Education, vol. 84, pp. 165-174, April 19951995.

2. S. Howe and J. Wilbarger, "2005 National Survey of Engineering Capstone Design Courses," in 2006 ASEE Annual Conference \& Exposition: Excellence in Education, Chicago IL, 2005.

3. A. Dennis, B. H. Wixom, and D. Tegarden, Systems Analysis and Design with UML Version 2.0: John Wiley and Sons, 2005.

4. D. Davis, S. Beyerlein, P. Thompson, K. Gentili, and L. McKenzie, "How Universal are Capstone Design Course Outcomes?," in 2003 ASEE Annual Conference \& Exposition: Staying in Tune with Engineering Education, Nashville TN, 2003.

5. M. Arvidsson and I. Gremyr, "Principles of robust design methodology," Quality and Reliability Engineering International, vol. 24, pp. 23-35, Feb 2008.

6. N. Ashrafi, Object-oriented systems analysis and design. Upper Saddle River, NJ: Prentice Hall, 2008.

7. T. Baines, H. Lightfoot, G. M. Williams, and R. Greenough, "State-of-the-art in lean design engineering: a literature review on white collar lean," Proceedings of the Institution of Mechanical Engineers Part BJournal of Engineering Manufacture, vol. 220, pp. 1539-1547, Sep 2006.

8. G. Cutts, Structured systems analysis and design methodology, 2nd ed. Oxford [England] ; Boston: Blackwell Scientific Publications, 1991.

9. G. C. Dandy, Planning and design of engineering systems, 2nd ed. New York: Taylor \& Francis, 2007.

10. B. M. Lunt, J. J. Ekstrom, S. Gorka, G. Hislop, R. Kamali, E. Lawson, R. LeBlanc, J. Miller, and H. Reichgelt, "Information Technology 2008: Curriculum Guidelines for Undergraduate Degree Programs in Information Technology," ACM/IEEE CSNov 20082008.

11. T. L. M. Kennedy, A. Smith, T. A. Wells, and B. Wellman, "Networked Families," Washington D.C.: PEW INTERNET \& AMERICAN LIFE PROJECT, 2008.

12. J. DeFrain, "Strong families," Family Matters, pp. 6-13, Winter 1999. 
13. S. Jamieson and L. Wallace, "Building Strong Families--Family Strengths," in Building Strong Families: University of Missouri, 2006.

14. T. L. Kennedy, A. Smith, A. T. Wells, and B. Wellman, "Networked families Parents and spouses are using the internet and cell phones to create a "new connectedness" that builds on remote connections and shared internet experiences," Pew19 Oct 2008.

15. M. Rupured and S. Quick, "Family Vitality: characteristics of strong families," in Cooperative Extension Service, 1989, pp. 1-4. 